\title{
ENTREVISTA COM A PROFA. DRA. NORA KRAWCZYK
}

Marian Dias

mariandias.dias@gmail.com Docente do Programa de Pós-Graduação em Educação da Universidade Federal de São Paulo 
1. Em 2014 a sra. publicou um artigo descrevendo a influência do empresariado nas políticas educacionais do EM¹. De lá para cá, avalia que outras forças vieram a se contrapor a essa tendência? Quem, atualmente, “dá as cartas" nas diretrizes do EM?

Considero que de 2014 para cá a influência do empresariado nas politicas educacionais tem se aprofundado. Naquele momento, observei o início de um processo, que chamei de renovação da racionalidade pedagógica e organizacional do ensino médio, que revelava o papel privilegiado de uma fração do empresariado nessa renovação. Também me dei conta de um forte processo de fragmentação, no interior das redes estaduais e de sua gestão politico educacional. A reforma atual do ensino médio só confirma essa tendência.

De lá para cá, o empresariado enquanto interlocutor privilegiado de muitas das secretarias estaduais e, principalmente, do governo federal executivo e legislativo - só tem aprofundado sua influência, anulando qualquer espaço de debate e participação de outros setores da sociedade. Um

\footnotetext{
1 Nora Krawczyk. Ensino médio: empresários
} dão as cartas na escola pública. Educ. Soc., exemplo claro disto foi o que aconteceu comPL n 6840de 2013, barrado pelo Movimento Nacional em Defesa do Ensino Médio, formado por várias entidades e pesquisadores. Um ano antes, em 2012, tinha sido criada uma comissão especial na Câmara de Deputados, destinada a propor uma reformulação do ensino médio. $\mathrm{O}$ argumento para a criação dessa Comissão era o mesmo que levou a aprovar a Medida Provisória (MP)do governo Temer:o ensino médio oferecido estaria correspondendo às expectativas dos jovens, especialmente no tocante à sua inserção na vida profissional, era necessário oferecer-lhes uma diversidade de opções formativas para poder fixar os jovens na escola e que seu rendimento pudesse melhorar.

Em síntese, propunham-sea ampliar a jornada escolar ea reformular a organização curricular, limitar as condições de acesso ao ensino noturno para os jovens maiores de 18 anos e a formação docente, por áreas. Propunhase que o currículo fosse organizado em quatro áreas de conhecimento: linguagem, matemática, ciências da natureza e humanas, com prioridade para Língua Portuguesa e Matemática. O

Campinas, v. 35, n. 126, p. 21-41, jan..-mar. 2014. 
ensino médio passaria a ter uma base comum nos dois primeiros anos e uma parte diversificada no terceiro ano, com diferentes opções formativas: formação profissional, ciências da natureza ou ciências humanas.

No relatório da Comissão está claramente explicitada a participação predominante de pessoas ligadas ideologicamente às propostas do setor privado: algumas secretarias de educação, outros órgãos públicos e instituições ligadas diretamente ao empresariado.

Nos finais de 2013, esse projeto sofreu várias mudanças, devido às pressões do MovimentoNacional em Defesa do Ensino Médioe seu substituto acabou sendo engavetado, porque tinha abandonado seus principais propósitos ${ }^{2}$.

Trago isto para mostrar que a reforma proposta como MP pelo governo Temer já estava sendo planejada por setores ligados ao empresariado vários anos antes, mas que não conseguiram pela pressão social e que agora tem todo o espaço político para poder realizá-la.

\footnotetext{
${ }^{2}$ Uma análise detalhada desse processo pode ser encontrado em: Silva, M. Ribeiro e Krawczyk, N. Quem é e o que propõe o PL de reforma do ensino médio Monica e Nora "entrevistam" o Projeto de Lei 6.840. Carta Educação, 21 de julho
}

A reforma do ensino médio proposta atualmente é uma versão similar à proposta do PL, porém ainda mais antidemocrática, tanto pelo fato de que desregulamenta toda a organização do ensino médio, quanto pelo risco de aprofundamento das desigualdades educacionais e sociais já presentes em nosso País.

Outro exemplo claro do lugar do empresariado hoje na educação brasileira e, portanto, na formação de nossas crianças e jovens é a forte inclusão da ideologia do empreendedorismo nas escolas, tornando o empresário como o novo herói. Isto é uma proposta 'pedagógica', a partir da qual o jovem passa a se visualizar como um empresário de si mesmo e passa a construir seu projeto de vida para poder ter êxito em outra etapa da sua vida. $\mathrm{O}$ prazer da vida presente relegada em função do esforço necessário para poder realizar seu 'sonho' de futuro.

O propósito da escola é formar jovens autônomos, criativos e empreendedores. Que compreendam que se precisa de esforço e de boas escolhas para conseguir o que se deseja. Essa

\footnotetext{
de 2015. Disponível em: <http://www.cartaeducacao.com.br/opiniao/pesq uisadoras-conversam-com-pl-6-840-de-reformado-ensino-medio>. Acesso em 18 out. 2017.
} 
ideologia coloca o jovem como único responsável de seu destino edescaracteriza do papel social da escola e da formação de um jovem autônomo. A verdadeira autonomia só se conquista através de uma formação sólida, que permita ao jovem compreender a sociedade contemporânea, de forma crítica. Só assim ele poderá, de fato, enfrentar os problemas que a vida colocará em seu caminho e exercer uma verdadeira cidadania.

2. Como a sra. avalia a flexibilização proposta pela nova reforma do EM? Quais as implicações disso, tanto para a formação dos jovens quanto para a organização institucional, considerando a infraestrutura necessária e a disponível nas escolas?

A primeira coisa que devemos nos perguntar é para que se quer flexibilizar ${ }^{3}$. A reforma atual pretende-se legitimar sob a égide da flexibilização, como se por si só a flexibilização do

3 Para este tema ver: KRAWCZYK, N. e FERRETT, C: Flexibilizar para quê? meias verdades da "reforma". Retratos de Escola v.11, n.20, Brasília: CNTE, jan/jun, 2017. Disponível tempo escolar, do conteúdo curricular e outros aspectos pudessem melhorar o ensino médio. É importante perceber que a ideia de flexibilização como solução de todos os problemas vem sendo utilizada, nas últimas décadas, não somente para pensar a educação. Ela se opõe a uma estrutura estatal de proteção do trabalho e de proteção social, que afeta todos os espaços públicos.

$\mathrm{Na}$ verdade, o que a Lei de reforma do ensino médio propõe é a regulamentação do ensino médio e não simplesmente a sua flexibilização curricular. Por isso, afirmamos que se for implementada esta reforma corre-se o risco da precarização e da desagregação do ensino médio brasileiro.

Vejamos alguns exemplos: se reduz o número de disciplinas obrigatórias e se inclui disciplinas optativas, em forma de opções formativas. As disciplinas obrigatórias, isto é matemática, português e inglês serão oferecidas durante os 3 anos de

em:

$<$ http://retratosdaescola.emnuvens.com.br/rde/ar ticle/view/757>. Acesso em 18 out. 2017. 
ensino médio e deverão responder ao padrão das avaliações nacionais. Os demais conteúdos da formação geral que comporão as até 1.800 horas reservadas para a formação geral, poderão ser oferecidos em forma de disciplinas, componentes curriculares e/ou estudos obrigatórios. As opções formativas são Linguagens, Matemática, Ciências Naturais, Ciências Humanas e Educação Profissional. O tempo reservado aos percursos formativos, inclusive com a extensão do tempo escolar diário, deixa clara a intencionalidade de valorização de tais percursos, em detrimento da formação de caráter mais amplo. A parte diversificada em opções formativas é justificada mais uma vez na diversidade de interesses dos alunos e na necessidade de lhes oferecer possibilidades de escolha do que aprender. Este argumento é claramente uma falácia, porque não é o aluno que terá a possibilidade de escolher e sim os governos estaduais. Eles são os que decidirão, segundo suas condições materiais e técnicas e seu projeto educacional, quais serão as opções formativas oferecidas e onde. Isto significa que em alguns estados e/ou em algumas escolas poderá se oferecer uma ou várias opções formativas e que o aluno terá como opções o que o estado e a escola lhe ofereçam.Tampouco a redução do tempo e conteúdo da formação comum a todos é uma escolha dos alunos, o que foi demonstrado nas mobilizações e nas demandas juvenis que buscam uma formação realmente integral.

A responsabilidade da definição da estrutura e da organização curricular, como o caso da Lei de Diretrizes e Bases, dos Planos Nacionais de Educação, das Diretrizes Curriculares Nacionais estabelecidas, que deveriam ser de nível nacional, garantindo critérios comuns de oferta para os estudantes, independentemente do Estado onde tenham sua residência, fica reduzida a um conjunto de "possibilidades" enunciadas na Lei, a serem decididas pelos estados, o que tende a agudizar a segmentação e a desigualdade regional.

A obrigatoriedade de cursar um dos trajetos formativos oferecidos pelo seu estado ou escola promove nos jovens uma formação fragmentada, que fraciona o conhecimento, em prol de um futuro exercício profissional e que, além do mais, discrimina os mais pobres, inibindo a possibilidade de "desafiar destinos, de ser uma coisa diferente do que somos hoje", como afirma o prof.

Olh@res, Guarulhos, v. 5, n. 2, novembro 2017. 
Nóvoa, em uma entrevista à Revista Carta Educação, aqui no Brasil ${ }^{4}$.

Outros exemplos de desregulamentação vamos encontrar na expansão do horário escolar, na flexibilização das condições de trabalho e profissão docente.

3. Qual a sua opinião sobre a divisão entre formação geral e formação profissionalizante, no EM?

Essas duas opções sempre existiram. Ela se torna cada vez mais problemática, levando em conta as novas

por uma formação que a princípio é incongruente com a visão do mundo do trabalho, nos moldes do capitalismo atual, a não ser que se queira treinar os jovens para serem simplesmente operários no chão da fábrica ou trabalhadores sem chances no mercado formal, travestidos de 'empreendedores'.

4. Com relação ao currículo, a disciplina de Artes considerada facultativa no 20 e 30 anos do ensino médio e obrigatória no 10 ano do ensino médio com apenas uma aula, foi excluída nos anos finais demandas do Na verdade, o que a Lei de do EM nas escolas mercado de reforma do ensino médio trabalho e uma propõe é a regulamentação do consciência maior da necessidade de uma formação que possa ir além dessas demandas. ensino médio e não simplesmente a sua flexibilização curricular. Por isso, afirmamos que se for implementada esta reforma corre-se o risco da $\mathrm{O}$ ensino médio precarização e da brasileiro teve desagregação do ensino médio muitas mudanças brasileiro.

nesse sentido, às vezes mais orientadas a responder as demandas do empresariado, outras orientadas a integrar ambas as formações. Este foi o caso do Ensino Médio integrado, que nunca foi suficientemente avaliado e se opta hoje movimento de exclusão de determinadas disciplinas do currículo nas últimas décadas?Que tipo de ajustes a reforma atual poderá impor aos currículos?

${ }^{4}$ CARTA EDUCAÇÃO: Se fosse brasileiro, estaria indignado com a situação da educação. Entrevista do prof. António Nóvoa, 28/03/2017. 
É interessante que a nova Lei faz referência à educação integral, mas entendida como a extensão do tempo do jovem na escola. Mas, para que? $\mathrm{Na}$ verdade a reformulação curricular proposta acaba com a possibilidade de uma educação integral. Rompe-se o caráter historicamente elitista do ensino médio, com uma proposta educacional imediatista, instrumental e, portanto, pragmática e reducionista. Não é difícil compreender o que está por trás da redução das disciplinas obrigatórias, se prestarmos atenção ao atrelamento do conteúdo ensinado na escola às avaliações nacionais e internacionais,às quais hoje as escolas e os estudantes estão submetidos. Na Lei está claramente dito que a União se reserva à definição de padrões de desempenho que serão a base dos sistemas nacionais de avaliação. Lamentavelmente, estamos mais uma vez frente a uma equação economicista para pensar a educação. A eficiência das políticas é medida pela melhor relação custo-benefício e pelos resultados mensuráveis.

\section{Sabemos que o ensino} médio brasileiro historicamente teve um caráter elitista. Esse cenário se modificou nas últimas décadas? A partir da reforma proposta recentemente pelo governo, quais são as chances de que isso se altere?

Sem dúvida, a partir dos anos 80 do século passado estamos frente a um processo importante de expansão do ensino médio e inclusão de novos setores sociais. Porém, essa expansão foi significativa até aproximadamente 2014 e, de lá para cá, o ensino médio está quase estagnado em algumas regiões e vem decrescendo em outras. Além disso, os índices de fracasso e evasão escolar continuam sendo significativos. Por exemplo, o censo escolar mostra que em 1991 tínhamos aproximadamente 3.800.000 jovens no ensino médio, em 2004 este número cresceu para, aproximadamente, 9.200.000 e em 2016 diminui para 8.150 .000 jovens, aproximadamente. Os motivos para este decrescimento da matricula do ensino médio não têm sido suficientemente estudados.

Além destes dados devemos levar em conta a defasagem idade série e o fracasso escolar, ambos ainda bastante significativos. A solução dos problemas educacionais já não pode ser mais pensada exclusivamente com reformas educacionais. É necessário reconhecer que a educação precisa de um projeto de longo prazo, com políticas intersetoriais que possam melhorar as condições das 
escolas ensinarem e dos jovens apreenderem. Sinceramente, não vejo de que forma a proposta de reforma do ensino médio possa melhorar esta situação, sendo que ela deixa o futuro da educação brasileira nas mãos de projetos estaduais, o que, levando em conta a desigualdade regional de nosso país, tende a produzir a precarização e desagregação do ensino médio.

Nesta configuração de desregulamentação de responsabilidades, a União se reserva, como já disse,àdefinição de padrões de desempenho que serão a base dos sistemas nacionais de avaliação. Ou seja, a aparente flexibilidade na definição dos conteúdos gerais fica submetida à definição predeterminada dos padrões de desempenho e legitimada pelas avaliações nacionais.

Além disso, esta reforma não pode ser pensada, isolada do contexto político de redução das conquistas sociais, de cortes do orçamento para educação e de pressões oriundas de setores fundamentalistas e homofônicos que as escolas e a sociedade como um todo vêm sofrendo, atingindo a autonomia docente, por meio da censura aberta ou velada.

\section{Por que o sistema} educativo brasileiro sofreu/sofre tantas reformas? Quais as consequências dessa dinâmica das

políticas educacionais?

A informação disponível sobre e para a educação cresce dia a dia e de forma exponencial, dominando cada vez mais 0 cenário midiático. Mas isso pode ser uma faca de dois gumes. A sociedade está mais informada, mas, ao mesmo tempo, o discurso alarmista, justificado pela invasão de informações negativas sobre o desempenho das escolas públicas brasileiras, tem criado condições para mudanças constantes, no âmbito legal e a busca de soluções rápidas e até mágicas, tanto para a escola como para o futuro dos jovens. Ao mesmo tempo, essas mudanças constantes resultaram, nas últimas décadas, em um conjunto de leis, resoluções, decretos, emendas, uns substituindo outros e sem uma avaliação de seus resultados, sobrepondo o tempo político ao tempo necessário para efetivamente realizar mudanças na educação. A descontinuidade das 
políticas gera o desalento pela falta de reconhecimento do esforço, que significa para a comunidade educativa implementar as mudanças propostas e a decorrente indiferença frente a novas situações. As consequências dessa hiperatividade de reformas são sofridas dia a dia pelos docentes e jovens: muda tudo para que tudo fique igual.

\section{Afinal, qual é a identidade do ensino médio brasileiro?}

É uma pergunta importante e que muitos constantemente se fazem, mas que não tem uma resposta simples nem unânime. É uma pergunta que está associada à que você fez anteriormente: porque o ensino médio sofre tantas mudanças? São perguntas que põem em cheque o caráter elitista que historicamente teve o ensino médio em nosso país. Um ensino médio produtor de desigualdades educacionais e, portanto, uma instância de aprofundamento das desigualdades sociais.

A falta de consenso em torno da identidade do ensino médio (formação geral e/ou formação profissional), as constantes reformas na sua estrutura, passando de uma organização única a uma organização com diferentes orientações e vice-versa, e as demandas constantes para inclusão e/ou exclusão de novos conteúdos no currículo são exemplos das tensões constantes,em torno desse nível de ensino.

$\mathrm{Eu}$ diria que a identidade do ensino médio está no fato de ser particularmente sensível às mudanças ocorridas, a partir da segunda metade do século XX. Nele, mais do que em qualquer outro nível de ensino, expressaram-se de forma contundente as transformações de ordem social, econômica e cultural que afetaram profundamente toda a educação pública, em diferentes países. Portanto, é na definição de políticas para o ensino médio que se têm dado os debates mais controversos, as constantes problematizações, os maiores impasses.

Não tenho dúvidas da necessidade de recuperar um lugar significativo para a escola, na formação e no cotidiano de nossos jovens. O jovem está acuado pela incerteza do mundo do trabalho, o que o leva a uma atitude imediatista, em suas expectativas em relação à escola. Nós devemos questionar isso com eles. Não tenho dúvidas de que a escola pode oferecer os instrumentos necessários para se tornar um espaço de reflexão, que questione uma adaptação passiva frente à realidade atual e permita a expansão das potencialidades humanas. 
Estamos em um momento histórico no qual as transformações de ordem social, econômica e cultural aguçam conflitos, exacerbam os processos de exclusão social e revitalizam o individualismo, os interesses privados e o consumo. Portanto, é uma época difícil para encarar um projeto democrático de educação pública e de verdadeira inclusão no mundo do conhecimento, mas não impossível. 